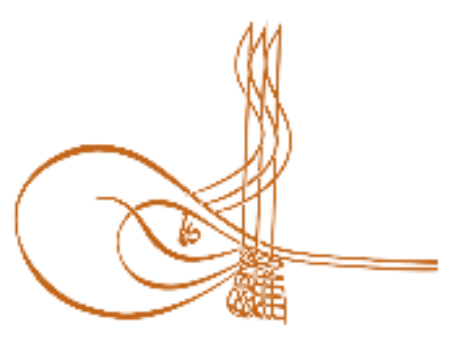

www.turkishstudies.net/turkishstudies
Turkish Studies

eISSN: $1308-2140$

Research Article / Araştırma Makalesi

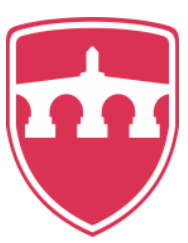

INTERNATIONAL

BALKAN

UNIVERSITY

Sponsored by IBU

\title{
Ortaöğretim Öğrencileri İçin Değerlendirme Deneyimi Ölçeğini Uyarlama Çalışması
}

\author{
Adaptation of Assessment Experience Questionnalre for Secondary School Students
}

\author{
Emine Kahraman $^{*}$ - Özlem Koray ${ }^{* *}$ - Seçil Turan ${ }^{* * *}$ - Özgür Murat Çolakoğlu ${ }^{* * * *}$
}

\begin{abstract}
In education, the experiences of students related to factors such as students, teachers, teaching methods, teaching materials. What students experience in the process; the amount and distribution of study efforts, examinations and learning, assignments and learning are included in the assessment process. In this context, the lack of a valid and reliable instrument that can measure the assessment experience of existing students to determine the amount of study and the nature of the assignments is remarkable. In this study, the Assessment Experience Questionnaire(AEQ), originally developed by Gibbs and Simpson (2003), was adapted to Turkish. The study is important in terms of being a source of data and providing the students' current assessment experiences. During the scale development process, additional items were included to the scale by literature review and final version of it was formed. The study group of the study consisted of 222 students for the first application and 1041 students for the last application. The AEQ consists of three subdimensions; the amount and distribution of the study effort, the examination and learning, assignments and learning. Some items have been eliminated from the adapted instrument because loading of the factors that make up the factors into more than one factor, factor load values are at least 3 items, and statistically, factorforming substances are theoretically in the same factor structure. Data were analyzed by exploratory factor analysis using the SPSS. To conduct the reliability and validity analyses of the scale, item analysis, factor
\end{abstract}

Bu makale Prof. Dr. Özlem KORAY'ın danışmanlığını yaptığı Seçil TURAN'ın yüksek lisans tezinden üretilmiştir. * Arş. Gör., Zonguldak Bülent Ecevit Üniversitesi, Ereğli Eğitim Fakültesi, Matematik ve Fen Bilimleri Eğitimi Bölümü Res. Asst. Zonguldak Bulent Ecevit University, Ereğli Faculty of Education, Mathematics and Sciences Department ORCID 0000-0002-0721-9545 eminekahraman07@gmail.com

*** Prof. Dr., Zonguldak Bülent Ecevit Üniversitesi Ereğli Eğitim Fakültesi, Matematik ve Fen Bilimleri Eğitimi Bölümü Prof. Dr., Zonguldak Bulent Ecevit University, Ereğli Faculty of Education, Mathematics and Sciences Department ORCID 0000-0003-1804-0871

ocankoray@gmail.com

*** Öğretmen, Kdz Ereğli Mehmet Ali ve Kadri Yılmaz Anadolu Lisesi

Teacher, Mehmet Ali and Kadri Yllmaz Anatolian High School

ORCID 0000-0002-0146-5788

sclturan@hotmail.com

${ }_{* * * *}$ Dr. Öğr. Üyesi, Zonguldak Bülent Ecevit Üniversitesi, Ereğli Eğitim Fakültesi, Eğitim Bilimleri Bölümü Asst. Prof. Dr., Zonguldak Bulent Ecevit University, Ereğli Faculty of Education, Educational Sciences Department ORCID 0000-0001-7258-4007

ozgurmat@ hotmail.com

Cite as/ Atıf: Kahraman, E., Koray, Ö., Turan, S., Çolakoğlu, Ö. M. (2020). Ortaöğretim öğrencileri için değerlendirme deneyimi ölçeğini uyarlama çalışması, Turkish Studies, 15(1), $283-295$. https://dx.doi.org/10.29228/TurkishStudies.39332

Received/Geliş: 17 October/Ekim 2019

Accepted/Kabul: 25 February/Şubat 2020

Copyright (C) MDE, Turkey

Checked by plagiarism software

Published/Yayın: 29 February/Şubat 2020

CC BY-NC 4.0 
analysis, and reliability coefficient were found. A scale of 13 items was formed from the item pool consisting of 31 items before the application of the scale. The adapted scale can be used to reveal the assessment experiences of different groups of students.

Structured Abstract: Introduction: In education, assessment is made process-oriented to decide what students learn in learning environments or to reveal the effectiveness of the implemented method, to determine the deficiencies or learning needs of students and to determine the rate of achieving the objectives in general (Doğan, 1997; Liu ve Carless, 2006; Marsh ve Willis, 2007; OECD, 2005). Through assessment, students' performances can be determined using a variety of assessment instruments (Linn ve Gronlund, 1995). It is also the guide to ensure that decisions about programs, teachers, students, and administrators, which are the basis of the education system, are accurate, reasonable and appropriate to the objectives (Bahar, Bıçak, Durmuş and Nartgün, 2014).

Academic achievement is one of the most important concepts to be measured during the assessment process. It is necessary to encourage students to study to increase their academic success and to perform as expected. Students who do not pay enough time and effort for academic studies have low motivation to actualize themselves at school. These students generally find enough effort to pass their class and think that more is unnecessary (Yavuzer, 1994). The student's expected academic achievement can be defined through learning-oriented assessments.

The quality of assessments used in education is important for students' development and academic achievement. The assessment experiences of the students in the learning process include all experiences related to the students, teachers, teaching methods and teaching materials. What students experience in the process; the amount and distribution of study efforts, examinations and learning, assignments and learning are included in the assessment process. In this context, the lack of a valid and reliable instrument that can measure the assessment experience of existing students to determine the amount of study and the nature of the assignments is remarkable. The Assessment Experience Questionnaire was adapted to address this deficiency. The adaptation process of the scale was based on the Assessment Experience Questionnaire (AEQ) developed by Gibbs and Simpson (2003). Besides, new items were added and the final version of the scale was formed by reviewing the literature during the adaptation process. During the scale development process, additional items were included to the scale by literature review and final version of it was formed. The study is important in terms of being a source of data and providing the students' current assessment experiences.

\section{Method}

The Assessment Experience Questionnaire (AEQ) developed by Gibbs and Simpson (2003) was adapted. The original scale consists of six sub-dimensions and each sub-dimension consists of six items. In this study, amount and distribution of study effort, assignments and learning, and the examination and learning sub-dimensions were examined. The reason for using three sub-dimensions of the original scale in this study is that the differentiation of items related to feedback and expressions of general assessment experience in the conceptual formation. While the three related sub-dimensions of the Assessment Experience Questionnaire scale were adapted to Turkish, the scale was first translated from English to Turkish by three field experts with English language proficiency and the Turkish form of the scale was constructed. The scales, which were translated from English to Turkish by three field experts, were examined by two field experts and the scale was provided in one form. Then, the scale was evaluated by two assessment experts and the final form of the scale was formed. In addition to the scale items developed by Gibbs and Simpson (2003), researchers attended an in-depth literature review and added new items to existing items. Supplementary items related to the factors constituting the contents of the scale were added by the researchers with the opinion of experts. The last version of the scale was formed with the attached items. The adaptation of the study and the new items were added thirty-one items before the implementation of the Assessment Experience Questionnaire. The scale consists of three factors: amount and distribution of study effort (7 items), examination and learning (12 items), assignments and learning (12 items). The firsth scale was applied to 222 secondary school students for validity and reliability analysis. The study group of the study consisted of ninth grade (62), tenth grade (52), eleventh grade (61), twelfth grade (47) students and a total of 222 students in the study. 112 females and 110 male students participated in the study. The scale was applied to a different group of 1041 students for construct validity. As a data collection instruments, the 
Assessment Experience Questionnaire was used. Data were analyzed by exploratory factor analysis using the SPSS package program. To conduct the reliability and validity analyses of the scale, item analysis, factor analysis, and reliability coefficient were found. For the construct validity of the scale, the scale was reapplied to a different sample group. Confirmatory Factor Analysis was performed by using the AMOS package program.

\section{Results}

Some items have been eliminated from the adapted instrument because loading of the factors that make up the factors into more than one factor, factor load values are at least 3 items, and statistically, factorforming substances are theoretically in the same factor structure. A total of 18 items were excluded from the scale: 2 items from the "amount and distribution of study effort", 8 items from the "exam and learning" dimension, 8 items from the "assignments and learning" dimension. In the first scale, as a result of the analyzes made on 31 items, the last version of the scale consists of 13 items. In the scale, distribution of items according to dimensions; The amount and distribution of study effort were determined as 5 items, examination and learning 4 items, assignments and learning 4 items. The internal consistency of the scale was found to be .84. Internal consistency coefficients for sub-dimensions; the amount and distribution of the study effort .71, the examination and learning .74, assignments and learning .83. As a result, it can be said that this scale is a reliable instrument to decide students' assessment experiences.

\section{Conclusion}

The adapted scale can be used to reveal the assessment experiences of different groups of students. The study is important in terms of being a source of data and presenting the students' current assessment experiences.

Keywords: Assessment, assessment experience, scale adaptation, secondary school students

Öz: Öğrenme süreci içerisindeki öğrencilerin değerlendirme deneyimleri öğretmen, öğrenci, öğretim materyali, öğretim yöntemi gibi unsurları kapsamaktadır. Değerlendirme deneyimi, öğrencilerin çalışma çabasının miktarını ve dağılımını, öğrencilerin öğrenme yaşantılarını, sınavların ve ödevlerin niteliğini içeren bir süreçtir. Bu bağlamda, öğrencilerin mevcut ödevlerin niteliğini ve çalışma miktarını tespit ederek değerlendirme deneyimlerini ölçen, geçerli ve güvenilir bir ölçme aracının eksikliği dikkat çekmektedir. Bu çalışmada orijinali Gibbs ve Simpson (2003) tarafindan geliştirilen (Assessment Experience Questionnaire) ölçeğinin Türkçeye uyarlaması amaçlanmıştır. Çalışma öğrencilerin varolan değerlendirme deneyimlerine yönelik veri kaynağı olması ve ortaya koyulması açısından önemlidir. Ölçek uyarlama sürecinde alan yazın incelenmiş ve ek maddeler eklenmiştir. Araştırmanın çalışma grubunu, ilk uygulama için 222 ve son uygulama için 1041 ortaöğretim öğrencisine uygulanmıştır. Değerlendirme Deneyimi Ölçeği; ödevler ve öğrenme, sınav ve öğrenme, çalışma çabasının miktarı ve dağılımı olmak üzere üç alt boyuttan oluşmaktadır. Uyarlanan ölçme aracindan; maddelerinin birden fazla boyuta yüklenmesi, her bir boyutun en az üç maddeden oluşması, boyut yükünün 3'ün üzerinde değer alması, istatiksel ve teorik olarak aynı boyutu oluşturan maddelerin aynı boyutta toplanması için bazı maddeler çıkarılmış̧ır. Veriler, SPSS kullanılarak Açıklayıcı Faktör Analizi ve AMOS kullanarak Doğrulayıcı Faktör Analizi yapılmıştır. Ölçeğin güvenirlik ve geçerlik analizlerinin yapılması için madde analizi ve güvenirlik katsayısı bulunmuştur. Ölçeğin uygulama öncesi ilk formu 31 maddeden oluşmaktadır. Uyarlama işlemleri sonrasında 13 maddelik bir ölçek formu oluşturulmuştur. Uyarlanan ölçek farklı grup öğrencilerinin değerlendirme deneyimlerini ortaya koymakta kullanılabilir.

Anahtar Kelimeler: Değerlendirme, değerlendirme deneyimi, ölçek uyarlama, ortaöğretim öğrencileri

\section{Giriş}

Eğitim, bireyi çağın şartları doğrultusunda yeterli ve ideal olarak yetiştirmeyi hedefler ve bu doğrultuda ortaya koyulan bütün çalışmalar nitelikli eğitim kapsamında değerlendirilir. Nitelikli eğitimin en önemli basamaklarından birisi de değerlendirmedir (Taras, 2002, 2003). Değerlendirme işlemi belli bir ölçüte göre, ölçmeden elde edilen sonuçların karşılaştırılması ve bir karara ulaşılması olarak tanımlanmaktadır (Atılgan, 2017; Semerci, 2008). Değerlendirme, ölçme 
yapıldıktan sonra yapılacak olan çalışmalara rehberlik etmektedir (Cemiloğlu, 2001). Eğitim sisteminde değerlendirme öğrencilere, öğretmenlere, yöneticilere ve programlara yönelik alınacak kararların hedefe uygun ve doğru olması için yol göstericidir (Bahar, Bıçak, Durmuş ve Nartgün, 2014). Değerlendirme, eğitim sürecinde öğrencilerin hedeflenen davranışlara ulaşabilme düzeylerinin ortaya koyulması ve öğrenme süreci hakkında bir yargıya varmak için yapılır. Değerlendirme yoluyla öğrencilerin performansları çeşitli ölçme araç ve gereçlerle belirlenebilir (Linn ve Gronlund, 1995). Uygulanan yöntemin etkililiğini ortaya koymak, öğrencilerin öğrenme ihtiyaçlarını ve eksikliklerini belirlemek için de sürece dayalı değerlendirme yapılabilir (Doğan, 1997; Liu ve Carless, 2006; Marsh ve Willis, 2007; OECD, 2005). Ancak çoğunlukla öğrenme ortamlarında öğrenciyi yetiştirme ve biçimlendirmeden uzak olan kısa cevaplı ve çoktan seçmeli testler, sözlü ve yazılı sinavlar gibi ürünü odağına alan değerlendirme yöntemleri tercih edilmektedir (Gelbal ve Kellecioğlu, 2007; Graue, 1993).

Değerlendirme süreci içerisinde ölçülmek istenen en önemli kavramlardan biri akademik başarıdır. Öğrencilerin kendilerinden beklenen performansları sergileyebilmeleri ve akademik başarılarını artırabilmeleri için çalışmaya yönelik teşvik edilmesi önemlidir. Akademik başarılarının arttırılmasına yönelik yeterince zaman ayırmayan ve çabalamayan öğrencilerin, okulda beklenen performansı gerçekleştirme motivasyonları düşüktür. Genellikle bu öğrencilerin akademik başarı algıları, sınıfı geçmelerini sağlayacak kadar çaba harcamaya ve zaman ayırmaya yeterli olduğu, fazla çalışmanın gereksiz olduğu şeklindedir (Yavuzer, 1994). Öğrencilerin akademik başarısı çalışmaya yönelik motivasyonlarının yüksek olmasından ve ders çalışma alışkanlıklarının gelişmişliğinden etkilenmektedir (Fidan, 1996). Öğrencinin kendisinden beklenen akademik başarı sürece dayalı olarak yapılan öğrenme odaklı değerlendirme türleri kullanılarak ortaya koyulabilir.

Akademik başarıyı etkileyen birçok faktör eğitim alanında yapılan çalışmalarda vurgulanmaktadır. Atılgan (1998) üniversite öğrencilerinin akademik başarıları ile ders çalışma alışkanlıkları arasındaki ilişkiyi incelediği araştırmasında ödevlerine yeterince özen gösteren ve zaman ayıran, planlı ve düzenli ders çalışan, zamanı etkin kullanan, gerekli olan durumlarda uzmanlardan yardım alabilen öğrencilerin diğer öğrencilere göre daha başarılı olduklarını belirlemiştir. Yiğit (2014) çalışmasında ortaokul öğrencilerinin iyi düzeyde ders çalışma alışkanlıklarının olduğunu, öğrencilerin düzenli ve planlı olarak çalıştıklarını ve ders çalışma sürecinde sessiz bir ortamı tercih ettiklerini belirtmiştir. Kızılboğa (2017) ortaokul öğrencilerinin akademik başarıları ile ders çalışma alışkanlıkları ve tutumları arasında ilişki olduğunu, öğrencilerin verimli zaman kullanma özellikleri ile ders çalışma becerilerinin birbiriyle orantılı olduğu sonucuna ulaşmıştır. Ayrıca öğretmene ve okula yönelik olumlu tutum gösteren öğrencilerin akademik başarısının yüksek olduğunu ortaya koymuştur. Yapılan çalışmalar öğrencilerin ders çalışma alışkanlıklarının ve ders çalışmaya ayrılan sürenin öğrencilerin öğrenmelerini etkilediğini ortaya koymaktadır. Bu çalışmada, Türkiye'de ortaöğretim seviyesinde öğrenim görmekte olan öğrencilerin değerlendirme deneyimlerinin ölçülmesi için öğrencilerin ödev ve sınavlara yönelik bakış açıları, ders çalışmaya ayrılan süreyi ve ders çalışma alışkanlıklarını inceleyen bir ölçme aracının alanyazına kazandırılması amaçlanmıştır.

Eğitimde kullanılan değerlendirmelerin kalitesi öğrencilerin gelişimi ve akademik başarısı açısından önemlidir. Öğrenme süreci içerisinde öğrencilerin değerlendirme deneyimleri öğretmen, öğrenci, öğretim materyali, öğretim yöntemi gibi unsurları kapsamaktadır. Bütün bu unsurlara yönelik olarak öğrencilerin yaşantılarına değerlendirme deneyimi denir. Değerlendirme deneyimi öğrencilerin çalışma çabasının dağılımını ve miktarını, öğrencilerin öğrenme yaşantılarını, sınavların ve ödevlerin niteliğini içeren bir süreçtir. Bu sürecin niteliğinin ortaya koyulması eğitim ve öğretimin değerlendirilmesi açısından önem kazanmaktadır. Bu bağlamda, öğrencilerin mevcut çalışma çabasının miktarını ve dağılımını, öğrenme yaşantılarını, sınavların ve ödevlerin niteliğini tespit etmek için geçerli ve güvenilir bir ölçme aracı olarak Değerlendirme Deneyimi Ölçeği (DDA) uyarlanmış ve alanyazına kazandırılmıştır. Ölçeğin uyarlanma sürecinde Gibbs ve Simpson 
(2003) tarafindan gerekli izinler alınarak geliştirilen (Assessment Experience Questionnaire) temel alınmıştır. Ayrıca ölçek uyarlama sürecinde literatür taraması yapılarak yeni maddeler eklenmiş ve ölçeğin son hali oluşturulmuştur. Çalışma, öğrencilerin değerlendirme deneyimlerini ortaya koyan ve değerlendirme deneyimlerine yönelik veri kaynăğ niteliğindedir.

\section{Yöntem}

Çalışmanın bu bölümünde araştırmanın deseninden, çalışma grubundan, ölçeğin uyarlama işlemlerinden bahsedilmiş, veri toplama araçlarıyla verilerin analizi açıklanmıştır.

\section{Araştırma Deseni}

Değerlendirme Deneyimi Ölçeğinin Türkçe'ye uyarlayarak geçerlilik ve güvenilirlik çalışmalarının yapıldığı bu çalışma ölçek uyarlama çalışmasıdır. Bu çalışmada mevcut olan durumu etkileme veya değiştirme kaygısı güdülmemiştir. Var olan şartlar doğrultusunda araştırma problemine yönelik veriler toplanmış ve gerekli analizler yapılmıştır.

\section{Çalışma Grubu}

2018-2019 eğitim-öğretim yılı içerisinde, Batı Karadeniz'de bulunan ortaöğretim devlet okullarının son sınıf öğrencileri araştırmanın çalışma grubunu oluşturmaktadır. Ölçekte yapı geçerliği için Açımlayıcı Faktör Analizinde 222 öğrenci, Doğrulayıcı Faktör Analizinde 1041 öğrenci çalışmaya dâhil edilmiştir. Bu öğrencilerden ilk uygulama için dokuzuncu (62), onuncu (52), on birinci (61) ve on ikinci (47) sınıf olmak üzere çalışmada toplam 222 ortaöğretim öğrencisi bulunmaktadır. Çalışmaya katılan öğrencilerin 112'si kız, 110'u erkek öğrencidir. Ölçeğin yapısal olarak geçerliliğini sağlamak için 1041 öğrenciden oluşan farklı bir örneklem grubundan veriler toplanmıştır. Bu grubu 470'i kız öğrenci 571'i erkek öğrenci oluşturmaktadır. Çalışmada amaçlı örneklem çeşitlerinden ölçüt örnekleme yöntemiyle örneklem belirlenmiştir. Amaçlı örneklem çeşitlerinden biri olan ölçüt örneklemde derinlemesine çalışılması gereken durumlarda zengin bilgi elde edilmesi için kullanılır (Patton, 1997).

\section{Uyarlama İşlemleri}

Araştırmada on ikinci, on birinci, onuncu ve dokuzuncu sınıf ortaöğretim öğrencilerinin değerlendirme deneyimlerini incelemek için orijinali Gibbs ve Simpson (2003) tarafindan geliştirilen Assessment Experience Questionnaire temel alınmıştır. Ölçeğin orijinali altı alt boyuttan ve her alt boyut altı maddeden toplamda otuz altı maddeden oluşmaktadır. Ölçek 5'li Likert tipi derecelendirmede olup 'hiç katılmıyorum' (1), 'katılmıyorum (2)', 'kararsızım (3)', 'katılıyorum (4)' ve 'kesinlikle katılıyorum (5)' şeklinde derecelendirilmiştir. Ölçeğe ait boyutlar; 'çalışma çabasının miktarı ve dağılımı, ödevler ve öğrenme, geribildirim miktarı ve zamanlaması, geribildirimin niteliği, geribildirim, sınav ve öğrenmedir. Bu çalışmada ise 'çalışma çabasının miktarı ve dağılımı, ödevler ve öğrenme, sınav ve öğrenme' alt boyutları dikkate alınarak ölçek uyarlaması yapılmıştır. Orijinal ölçeğin üç alt boyutunun bu çalışmada kullanılmasının nedeni ise geribildirimle ilgili boyutlarla genel değerlendirme deneyimi boyutlarının kavramsal yapıda birbirinden farklılaşmasıdır.

Assessment Experience Questionnaire'in ilgili üç alt boyutu Türkçeye uyarlaması yapılırken, öncelikle ölçek İngilizce dil yeterliliğine sahip üç alan uzmanı tarafından İngilizceden Türkçeye çevrilmiştir ve ölçeğin Türkçe formları oluşturulmuştur. İngilizceden Türkçeye uzmanların çevirmiş olduğu formlar iki alan uzmanı formları karşılaştırarak ölçeği tek form haline getirmiştir. Karş1laştırma sonucunda ortaya koyulan son ölçek formuna iki ölçme değerlendirme uzmanı inceleyerek değerlendirilmiştir. Orijinal ölçekte yer alan altı faktörden üçü olan 'çalışma çabasının miktarı ve dağılımı, sınavlar ve öğrenme ve ödevler ve öğrenme' boyutları bu çalışma için DDÖ’nin maddelerinin bir bölümünü oluşturmuş̧ur. Gibbs ve Simpson (2003)'ın geliştirdiği ölçek maddelerine ek olarak araştırmacılar tarafından derinlemesine bir literatür taraması yapılarak, 
var olan maddelere ek yeni maddeler eklenmiştir. Ölçeğe ait boyularla ilgili eklenen maddeler uzman görüşü alınarak eklenerek ölçeğin son hali oluşturulmuştur.

Araştırmada uyarlanan ölçek maddelerine eklenen yeni maddelerle birlikte ölçeğin uygulama öncesi son formunda toplam otuz bir madde bulunmaktadır. Bu maddelerin alt boyutlara göre dağılımı; 'çalışma çabasının miktarı ve dağılımı (7 madde), sınav ve öğrenme (12 madde), ödevler ve öğrenme (12 madde)' olarak belirlenmiştir. Ölçek, geçerlik ve güvenirlik incelemesi için 222 ortaöğretim öğrencisine bir ders saati süresince (40 dakika) uygulanmıştır.

\section{Veri Toplama Araçları}

Araştırmada 'Değerlendirme Deneyimi Ölçeği (DDÖ)' veri toplama aracı olarak kullanılmıştır. DDÖ, toplamda otuz bir maddeden ve üç boyuttan oluşmaktadır.

\section{Verilerin Analizi}

Uyarlanan ölçeğin güvenirlik ve geçerlik analizleri kapsamında madde analizi, faktör analizi ve güvenirlik katsayısı incelenmiştir. Ölçeğinin yapı geçerliği hem Açıklayıcı Faktör Analiziyle (AFA) hem de Doğrulayıcı Faktör Analizi (DFA) ile belirlenmiştir. AFA kapsamında faktör indirgeme yöntemi olarak temel eksen faktörleşme, faktör-madde dağılımları için ise varimax döndürülmüş bileşen matrisi incelenmiştir. DFA ise AFA ile elde edilen faktör-madde dağılımlarının araştırmadan bağımsız bir çalışma grubunda ne kadar sağlıklı sonuçlar verdiğini belirlemek için kullanılmıştır. Araştırma kapsamında yapılan AFA SPSS istatistik paket programı ile DFA ise AMOS istatistik paket programı ile yapılmıştır. Ölçeğin güvenirliği için iç tutarlılığa ilişkin Cronbach Alfa $(\alpha)$ analizleri yapılmıştır. Ölçeğin maddelerinin ayırt ediciliğinin tespiti için madde analizi yapılmıştır.

\section{Bulgular}

Bu bölümde ölçeğin geçerlik ve güvenirlik çalışmalarına ilişkin bulgulara yer verilmiştir.

\section{Değerlendirme Deneyimi Ölçeği (DDÖ) Güvenilirlik Çalışması}

Ölçeğe ait iç tutarlılık Cronbach Alfa $(\alpha)$ güvenirliği 0.84 olarak belirlenmiştir. İç tutarlılık bağlamında güvenirlik, ölçme aracı maddelerinin psikolojik ve kavramsal olarak tutarlı bir yapıda ölçme düzeyinin tespit edilmesi için hesaplanır. Hesaplanma sonucunda yüksek katsayılar ölçme aracının güvenilirliğinin yanında yapı geçerliğininde ortaya konmasında önemlidir (Baykul,1979). DDÖ'de bulunan maddelerin madde istatistiği olarak madde-toplam korelâsyonları hesaplanmıştır. Tablo1.'de verilen bu değerler her bir maddeden elde edilen puan ile toplam puan arasındaki ilişki anlamında kullanılmakta olup, her bir maddenin ölçeğin tamamı ile olan korelâsyon katsayısıdır. 


\begin{tabular}{|c|c|c|c|c|}
\hline No & Değerlendirme Deneyim Ölçeği Maddeleri & $\begin{array}{c}\text { Madde } \\
\text { ortalaması }\end{array}$ & $\begin{array}{c}\text { Madde } \\
\text { standart } \\
\text { sapması }\end{array}$ & $\begin{array}{c}\text { Madde toplam } \\
\text { korelasyonu }\end{array}$ \\
\hline $\mathrm{d} 1$ & $\begin{array}{l}\text { Bir ödevimin olup olmamasına bakmaksızın, } \\
\text { her hafta eşit miktarda çalışırım. }\end{array}$ & 2.78 & 1.04 & .34 \\
\hline $\mathrm{d} 3$ & $\begin{array}{l}\text { Bir derste başarılı olmak istiyorsam düzenli bir } \\
\text { şekilde çalışmam gerekir. }\end{array}$ & 4.34 & .94 & .30 \\
\hline d5 & $\begin{array}{l}\text { Sınav haftalarında çalışmaya daha fazla zaman } \\
\text { ayırırım. }\end{array}$ & 4.30 & .97 & .35 \\
\hline d6 & $\begin{array}{l}\text { Ödevlerin olduğu haftalarda çalışmaya daha çok } \\
\text { vakit ayırırım. }\end{array}$ & 3.37 & 1.06 & .42 \\
\hline $\mathrm{d} 7$ & $\begin{array}{l}\text { Zorlandığım konuları öğrenmek için çalışmaya } \\
\text { daha fazla zaman ayırırım. }\end{array}$ & 3.73 & 1.07 & .48 \\
\hline d9 & Sınavlara hazırlanırken yeni şeyler öğrenirim. & 3.82 & 1.03 & .35 \\
\hline d13 & $\begin{array}{l}\text { Ne öğrendiğimizin farkına varmamız için sınav } \\
\text { gereklidir. }\end{array}$ & 2.93 & 1.36 & .60 \\
\hline $\mathrm{d} 17$ & $\begin{array}{l}\text { Sınavlar bana göre öğrenmenin önündeki en } \\
\text { büyük engeldir. }\end{array}$ & 2.94 & 1.35 & .44 \\
\hline d15 & Sunavlar düzenli çalışabilmem için gereklidir. & 2.95 & 1.30 & .52 \\
\hline $\mathrm{d} 22$ & Ödevler beni daha çok çalışmaya teşvik eder. & 2.85 & 1.25 & .63 \\
\hline $\mathrm{d} 25$ & Ödevler benim için sıkıcı ve yorucudur. & 2.35 & 1.21 & .53 \\
\hline $\mathrm{d} 26$ & Ödevler öğrenmem konusunda etkili değildir. & 3.28 & 1.31 & .60 \\
\hline $\mathrm{d} 27$ & $\begin{array}{l}\text { Ödevleri gereksiz ve zaman kaybı olarak } \\
\text { görürüm. }\end{array}$ & 3.02 & 1.32 & .68 \\
\hline
\end{tabular}

Cronbach Alfa Katsayısı $(\alpha)=.84$

Tablo 1'de 13 maddelik ölçeğin son formunun madde-toplam korelasyonları .30 ile .68 arasında değiştiği görülmektedir. Ölçeğe ait iç tutarlılık katsayısı olan Cronbach Alpha değeri .84 olarak hesaplanmıştır.

\section{Değerlendirme Deneyimi Ölçeğinin Geçerlik Çalışması}

Bir ölçme aracının belirlenen bir değişken dışında başka değişkenlerden karıştırmadan arındırılarak ölçebilmesine geçerlik denir (Baykul, 2000). Geçerlik, ölçekde ölçülmesi beklenen özelliğin ölçekle olan uygunluğu için yapılır. Geçerliğin bir diğer unsurları arasında yapılan ölçümlerin ölçülmesi gereken özelliği yansıtıp yansıtmadığ 1 ve ölçümlerin kurallara uygun yapılıp yapılmadığı bulunmaktadır (Şencan, 2005). Çalışmada DDÖ'nin yapı geçerliğini hesaplanmasında AFA kullanılmıştır. AFA, bir niteliği veya yapıyı ölçebilen değişkenlerin olabilecek en az boyutta toplayarak açıklayan bir istatistiksel yöntemdir (Büyüköztürk, 2006). DDÖ’nün faktör analizine uygunluğunun belirlenmesinde Kaiser-Meyer-Olkin (KMO) Testi ve Bartlett Küresellik Testi ile ortaya konulmuştur. KMO testi $0-1$ aralığında değer alarak, faktör analizi uygunluğunun belirlenmesi ve değișkenler arasındaki korelasyonların hesaplanmasında kullanılır. Bu değer 1'e yaklaştıkça, ölçek maddelerinin oluşturduğu korelasyon matrisine faktör analizinin uygulanabilirliği artmaktadır. Tablo 2'ye göre DDÖ'ye ait KMO testi değeri 0.84 olarak hesaplanmıştır. Ölçekten elde edilen bu değere göre ölçekten elde edilen ölçümlerin faktör analizine uygun olduğunu göstermektedir (Şencan, 2005). Bartlett küresellik testi ise; m sayida ölçek maddesinin oluşturduğu $\mathrm{m}$ x m korelasyon matrisinin birim matrisi olup olmadığını test eden bir hipotezdir. Eğer $\mathrm{m}$ x m korelasyon matrisi birim matris ise, $\mathrm{m}$ sayıdaki değişkenin oluşturduğu $\mathrm{m} \times \mathrm{m}$ korelasyon matrisinin faktör analizi yapabilmek için uygun bir çözüme sahip olmadığı sonucu ortaya çıkmaktadır. Tablo 2'ye göre, bu çalı̧̧ma için Bartlett küresellik testi Ki-kare (ChiSquare) değeri anlamlı olarak tespit edilmiştir. Bu sonuca göre göre " $\mathrm{m}$ x m yapıdaki korelasyon 
matrisi birim matrisi değildir" hipotezi kabul edilerek, veri setinin faktör analizine uygun olduğu söylenebilir (BKTD=907.479; p<0.05).

Tablo 2: Değerlendirme Deneyim Ölçeğine Ait KMO Ve Bartlett's Test İstatistikleri

\begin{tabular}{lc}
\hline Kaiser-Meyer-Olkin (KMO) Örneklem Uygunluğu Ölçüsü & .84 \\
\hline Bartlett's Küresellik Testi Yaklaşık Ki-Kare Değeri & 907.48 \\
Serbestlik Derecesi (sd) & 78 \\
Anlamlllık Düzeyi (Sig.) & .00 \\
\hline
\end{tabular}

Faktör analizinde, faktör çıkarım metodu olarak temel eksen faktörleştirme ve ölçek maddelerinin faktörler altındaki dağılımını daha anlaşılır hale getirebilmek için varimax döndürme işlemi gerçekleştirilmiştir. Yapılan faktör analizi sonucunda DDÖ’nün birinci boyutu 'ödevler ve öğrenme'de 4 madde (d27, d26, d25, d22), 'çalışma çabasının miktarı ve dağılımı' boyutunda 6 madde (d5, d6, d7, d3, d9, d1) ve 'sinav ve ögrenme' boyutunda 3 madde (d13, d15, d17) bulunmuş olup toplam ölçekte 13 madde bulunmaktadır. Tablo 3'de DDÖ'nde yer alan maddelerin faktör yükleri ve boyutlara göre dağılımı belirtilmektedir.

Tablo 3: Değerlendirme Deneyimi Ölçeğinde Yer Alan Maddelerin Faktörlere Göre Dağılımı Ve Faktör Yükleri

\begin{tabular}{lccc}
\hline Madde & \multicolumn{3}{c}{ Faktörler } \\
\cline { 2 - 4 } No & $\begin{array}{c}\text { Ödevler ve } \\
\text { Öğrenme }\end{array}$ & $\begin{array}{c}\text { Çalışma Çabasının } \\
\text { Miktarı ve Dağılımı }\end{array}$ & $\begin{array}{c}\text { Sinavlar ve } \\
\text { Öğrenme }\end{array}$ \\
d27 & .769 & & \\
d26 & .713 & & \\
d25 & .622 & & .355 \\
d22 & .561 & .706 & \\
d5 & & .654 & \\
d6 & & .563 & \\
d7 & & .481 & \\
d3 & & .410 & \\
d9 & & .308 & .824 \\
d1 & & & .524 \\
d13 & & & .513 \\
d15 & & & \\
d17 & & & \\
\hline
\end{tabular}

* Faktör çıkarım metodu: Temel eksen faktörleştirme; Faktör döndürme metodu: Varimax

Tablo 3'de görüldüğü gibi birinci boyut faktör yükü .56 ile .78 arasında değişen 4 maddeden oluşmaktadır. İkinci boyut faktör yükü .31 ile .71 arasında değişen 6 maddeden oluşmaktadır. Üçüncü boyut faktör yükü ise .51 ile .82 arasında değişen 3 maddeden oluşmaktadır.

Tablo 4'e göre DDÖ’ne ait üç alt boyutun (faktörün) güvenirlik katsayısı sırasıyla $.83, .71$ ve .74 olarak hesaplanmıştır. Ölçme aracının birinci faktörü "ödevler ve öğrenme" şeklinde isimlendirilmiş olup, bu faktörün öz değeri 4.45 'dir. Birinci faktöre ilişkin açılanan varyans yüzdesi \% 34.27 olarak tespit edilmiştir. İkinci faktör "ç̧alışma çabasının miktarı ve dağılımı" olarak isimlendirilmiş olup, bu faktörün öz değeri 1.82'dir. Birinci faktöre ilişkin açıklanan varyans yüzdesi \% 13.96 olarak tespit edilmiştir. Üçüncü faktör "sınavlar ve öğrenme" olarak 
isimlendirilmiş olup, bu faktörün öz değeri 1.02'dir. Birinci faktöre ilişkin açılanan varyans yüzdesi \% 7.88 olarak tespit edilmiştir.

Tablo 4: Değerlendirme Deneyim Ölçeğinin Faktörlerine Ait Güvenirlik Katsayıları

\begin{tabular}{lccc}
\hline & $\begin{array}{c}\text { Ödevler ve } \\
\text { Öğrenme } \\
\text { (1. Faktör) }\end{array}$ & $\begin{array}{c}\text { Çalışma } \\
\text { Çabasını Miktarı } \\
\text { ve Dağılım } \\
\text { (2. Faktör) }\end{array}$ & $\begin{array}{c}\text { Sinavlar ve } \\
\text { Öğrenme } \\
\text { (3. Faktör) }\end{array}$ \\
\hline Cronbach Alfa $(\alpha)$ & .83 & 0.71 & 0.74 \\
Faktörlere Ait Özdeğerler & 4.45 & 1.82 & 1.02 \\
Açıklanan Varyans Yüzdesi & 34.27 & 13.96 & 7.88 \\
Açıklanan Yığılmalı Varyans Yüzdesi & 34.27 & 48.23 & 56.11 \\
\hline
\end{tabular}

DDÖ’nin üç faktörlü yapısının değerlendirme deneyiminin \%56.11'ini açıkladığı görülmektedir. Ölçeğin psikometrik özellikleri incelendiğinde ortaöğretim düzeyinde öğrenim gören öğrencilerin değerlendirme deneyimlerini belirlemek için geçerli ve güvenilir bir ölçme aracı olduğu söylenebilir.

\section{Doğrulayıcı Faktör Analizi (DFA)}

İlk uygulama sonrasında ölçeğin AFA yapılarak oluşturulan faktör ve maddeler arasındaki ilişkileri veren son formu farklı bir örneklem grubu üzerinde DFA'ya tabi tutulmuştur. DFA sonuçlarının geçerliliği için modele ait uyum iyiliği indekslerinin istenilen ölçütleri karşılaması gerekmektedir. Çalışmada orijinal ölçeğin maddelere ait boyutları belirlenmiş olduğu için doğrudan altı boyut üzerinden DFA yapılmıştır. Kurulan modelin DFA ile çözümlenmesi sonucunda elde edilen bulgular aşağıda verilmiştir. 13 maddenin üç alt boyuta ilişkin bağıntıları üzerine kurulu model uyum indeksleri açısından incelenmiştir. NFI (Normed Fit Index), GFI (Goodness-of-fit Index), AGFI (Adjusted Goodness of Fit Index), IFI (Incremental Fit Index) ve CFI (Comparative Fit Index) değerlerinin 0.90 'dan büyük değerlerde olması yeterli düzeyde uyumun olduğunu, bu değerlerin sıfıra yaklaşması kötü, bire yaklaşması mükemmel uyumu gösterir. RMSEA ise 0.05 'ten küçük olmasının iyi uyumu, 0.10 'in altında olması ise kabul edilebilir bir uyumu, ki-kare değerinin serbestlik derecesine oranın ise 5'in altında olmasının iyi uyumu gösterdiği belirtilmektedir (Çokluk, Şekercioğlu \& Büyüköztürk, 2010; Kline, 2005; Schumacker \& Lomax, 2004; Şimşek, 2007; Tabachnick \& Fidell, 2007; Yılmaz \& Çelik, 2009). Yapılan DFA'da elde modelin uyum indeksleri incelenmiş ve ki-kare değerinin $(\chi 2=558.070 \mathrm{~N}=1041, \mathrm{sd}=62, \mathrm{p}=0.00)$ manidar olduğu görülmüştür. Hesaplanan $\chi^{2} / \mathrm{df}$ oranı $\chi^{2} / \mathrm{df}=9.001$ bulunmuş ve 5 ten büyüktür. Örneklem sayısının büyüklüğü $\chi^{2} / \mathrm{df}$ oranına etki ederek bu değerin yüksek olmasına neden olmuştur. Kikare değeri modelin uygunluğu için kullanılan en temel ölçüm olsa bile bu istatistiğin kullanımında da sinırlılıklar bulunmaktadır. En önemli sınırlılıklardan birisi bu değerin örneklem büyüklüğü ile doğrudan ilişkisinin olmasıdır. Büyük örneklemlerde $(\mathrm{N}>50)$ çoğunlukla model uygunluğunu reddetmesidir (Bentler \& Bonnet, 1980; Jöreskog \& Sörbom, 1993; Kenny \& McCoach, 2003). Bu nedenle özellikle büyük örneklemlerde ki-kare istatistiğinin değerinin kullanılması eksik kalacaktır.

RMSEA değeri modelin uygunluğunu yorumlayarak en güvenilir bilgiyi veren istatistiksel modellerden biri olarak değerlendirilmiştir (Diamantopoulos, 2000). RMSEA değeri 0 ile 0.05 arasında iyi bir uyum değeri olduğunu, 0.05 ile 0.08 arasında olması ise kabul edilebilir bir uyum değeri olarak kabul edilmiştir (Byrne \& Campbell, 1999; Brown \& Cudeck, 1993). Bu çalışmada uyum indekslerinde ise RMSEA $=.08$ olup, bu değer kabul edilebilir bir uyumun olduğunu gösterdiği söylenebilir. $\mathrm{Bu}$ analizde hesaplanan uyum istatistikleri $\mathrm{CFI}=.85, \mathrm{NFI}=.83$ ve IFI $=.85$ değerleri bulunmuş ve .90 'a yakın değerler olmasına rağmen bu değerin altında kalmıştır. Yapılan hesaplamalara göre GFI değerinin 0.85 'ten ve AGFI değerinin 0.80 'den yüksek olması modelin verilerle olan uyumu için birer gerekçe olarak kabul edilebilmektedir (Anderson \& Gerbing, 1984; Cole, 1987; Marsh, Balla \& McDonald, 1988; Gülbahar \& Büyüköztürk, 2008). Bu çalışma için 
GFI=.92 ve AGFI= .88 değeri bulunarak, hesaplanan uyum indekslerine modelin uyumlu olduğu kabul edilebilir.

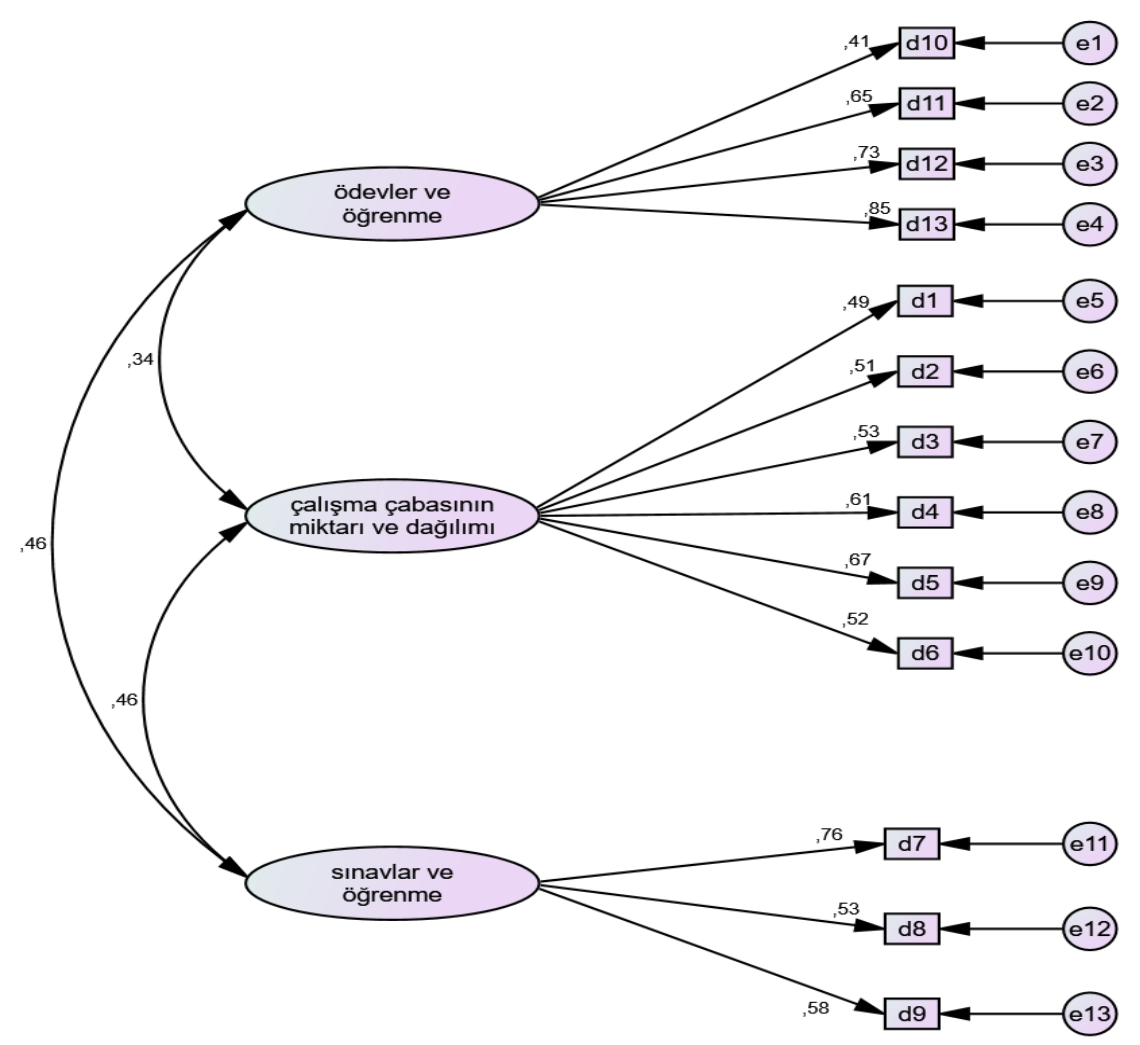

Şekil 1: Doğrulayıcı Faktör Analizi Modeli

DDÖ'ünün geçerlik çalışması için yapılan DFA sonucu elde edilen diyagram Şekil 1'de verilmiştir. $\mathrm{Bu}$ sonuçlar ölçeğin son haliyle kabul edilebilir seviyede uyum değerlerine ulaştı̆̆ söylenebilir. Şekil 1'de ölçeğin üç boyutlu yapısı doğrulanmış olup, maddelerinin faktör yükleri 0.41 ile 0.85 arasında değişmektedir.

\section{Sonuç ve Öneriler}

Uyarlanan ölçme aracından maddelerin birden fazla boyuta yüklenmesi, her bir boyutun en az üç maddeden oluşması, boyut yükünün 3'ün üzerinde değer alması, istatistiksel ve teorik olarak aynı boyutu oluşturan maddelerin aynı boyutta toplanması için bazı maddeler çıkarılmıştır. DDÖ'de 'çalışma çabasının miktarı ve dağılımı' boyutundan ( 2 madde), 'sınav ve öğrenme' boyutundan ( 8 madde) ve 'ödevler ve öğrenme' boyutundan ( 8 madde) çıkarılmış olup, ölçekten toplamda 18 madde çıkarılmıştır. Böylelikle uygulama öncesinde 31 maddelik ölçek formu, uygulama ve analizler sonucunda 13 maddeye düşmüştür. DDÖ analizler sonrasında üç boyuttan oluşmaktadır. Ölçek 'çalışma çabasının miktarı ve dağılımı' boyutunda (6 madde), 'sınav ve ögrenme' boyutunda (3 madde) ve 'ödevler ve öğrenme' boyutunda (4 maddeden) oluşmaktadır.

DDÖ'ye ait iç tutarlılık değeri Cronbach Alfa $(\alpha)$ güvenirliği 0.84 olarak hesaplanmıştır. Ölçeğin alt boyutlarına ilişkin güvenirliklerinin yüksek olması (ödevler ve öğrenme $=.83$; çalışma çabasının miktarı ve dağılımı $=.71$; sınav ve öğrenme $=.74$ ) alt boyutlardaki maddelerin birbiri arasında tutarlığını belirtmektedir. AFA sonuçlarına göre ölçeğin geçerliği belirlenmiştir. Yapılan analizler sonucunda geçerli ve güvenilir bir ölçme aracı olarak DDÖ ortaöğretim öğrencileriyle yapılacak çalışmalarda uygulanabilir. Araştırmanın bulguları öğrencilerin değerlendirme 
deneyimini ödev yapma ve sınav süreçlerinde gösterdiği davranışlarla ilişkili bir yapı olduğuna işaret etmektedir. Ölçekte bulunan bu yapıların öğrenci başarısını etkilediği söylenebilir.

Araștırma sonucunda elde edilen sonuçlara șu önerilerde bulunulabilir: kullanılabilir.

Uyarlanan ölçek farklı grup öğrencilerinin değerlendirme deneyimlerini ortaya koymakta

Öğrencilerin farklı demografik özellikler dikkate alınarak öğrencilerin değerlendirme durumları ortaya koyulabilir.

$\mathrm{Bu}$ çalışma ortaöğretim öğrencileriyle yapılmıştır. Yapılan bu çalışma dikkate alınarak farklı seviyedeki öğrencilerin değerlendirme deneyimlerini belirlemek için ölçme araçları geliştirilebilir.

\section{Kaynakça}

Anderson, J. C. \& Gerbing, D. W. (1984). The effect of sampling error on convergence, improper solutions, and goodness-of-fit indices for maximum likelihood confirmatory factor analysis. Psychometrika, 49, 155-173.

Atılgan, H. (2017). Ĕgitimde ölçme ve değerlendirme. Ankara: Anı Yayınları.

Atılgan, M. (1998). Üniversite öğrencilerinin ders çalışma alışkanlıkları ile akademik başarılarının karşılaş̧ırılması (Yayınlanmamış Yüksek Lisans Tezi). Gaziantep Üniversitesi Sosyal Bilimler Enstitüsü, Gaziantep.

Bahar, M., Bıçak, B., Durmuş, S., \& Nartgün, Z. (2014). Geleneksel-tamamlayıcı ölçme ve değerlendirme teknikleri ögretmen el kitabı. Ankara: Pegem Akademi.

Baykul, Y. (1979). Örtük özellikler ve klasik test kuramları üzerine bir karşılaştırma (Yayımlanmamış Doktora Tezi). Hacettepe Üniversitesi, Ankara.

Baykul, Y. (2000). Eğitimde ve psikolojide ölçme: klasik test teorisi ve uygulamast. Ankara: ÖSYM yayınları.

Bentler, P. M., \& Bonett, D. G. (1980). Significance tests and goodness of fit in the analysis of covariance structures. Psychological Bulletin, 88(3), 588.

Browne, M. W., \& Cudeck, R. (1993). Alternative ways of assessing model fit. Sage Focus Editions, 154, 136-136.

Büyüköztürk, Ş. (2006). Sosyal bilimler için veri analizi el kitabı. Ankara: Pegem A Yayıncılık.

Byrne, B. M., \& Campbell, T. L. (1999). Cross-cultural comparisons and the presumption of equivalent measurement and theoretical structure: A look beneath the surface. Journal of Cross-Cultural Psychology, 30(5), 555-574.

Cemiloğlu, M. (2001). Anadilimiz Türkçe.” Türk Yurdu Türkçeye Saygı Dergisi, 2(Özel Sayı), 162163.

Cole, D. A. (1987). Utility of confirmatory factor analysis in test validation research. Journal of Consulting and Clinical Psychology, 55, 1019-1031.

Çokluk, Ö., Şekercioğlu, G. ve Büyüköztürk, Ş. (2010). Çok değişkenli istatistik SPSS ve LISREL uygulamaları (Birinci baskl). Ankara: Pegem Akademi Yayınları.

Diamantopoulos, A. \& Siguaw, J. (2000). Introducing LISREL: A Guide for the Uninitiated (Introducing Statistical Methods Series). London: Sage Publications. 
Doğan, H. (1997). Eğitimde program ve ögretim tasarımı. Ankara: Önder Matbaacilık.

Fidan, N. (1996). Okulda ögrenme ve ögretme. İstanbul: Alkım Yayınevi.

Gelbal, Selahattin ve Hülya Kellecioğlu (2007); “Öğretmenlerin Ölçme Değerlendirme Yöntemleri Hakkındaki Yeterlik Algıları ve Karşılaştıkları Sorunlar," Hacettepe Üniversitesi Eğitim Fakültesi Dergisi, Cilt 33, Say1 4, s. 135-145.

Gibbs, G., \& Simpson, C. (2003). Measuring the response of students to assessment: the assessment experience questionnaire. 11th Improving Student Learning Symposium, 26-30 Ağustos, Padova, s.3-31.

Graue, M. Elizabeth (1993); "Integrating Theory and Practice Through İnstructional Assessment," Educational Assessment, Cilt 1, Say1 4, s. 283-309.

Gülbahar, Y \& Büyüköztürk, Ş. (2008). Değerlendirme Tercihleri Ölçeğinin Türkçeye Uyarlanmas1, Adaptation Of Assessment Preferences Inventory To Turkısh. Hacettepe Üniversitesi Eğitim Fakültesi Dergisi (H. U. Journal of Education), 35, 148-161.

Jöreskog, K. G., \& Sörbom, D. (1993). LISREL 8: Structural equation modeling with the SIMPLIS command language. Mooresville: Scientific Software International.

Kenny, D. A., \& McCoach, D. B. (2003). Effect of the number of variables on measures of fit in structural equation modeling. Structural Equation Modeling, 10(3), 333-351.

Kızılboğa, M. (2017). 7. sınıf öğrencilerinin çalışma alışkanlıkları ve tutumlarının akademik başarı ile ilişkisi (Yayınlanmamış Yüksek Lisans Tezi). Toros Üniversitesi Sosyal Bilimler Enstitüsü, Mersin.

Kline, R. B. (2005). Principles and practice of structural equations modeling. New York: Guilford.

Linn, R., \& Gronlund, N. (1995). Measuremant and assesment in teaching, Upper Saddle River: Printice-Hall Inc.

Liu N. F., \& Carless, D. (2006). Peer feedback: the learning element of peer assessment. Teaching in Higher Education, 11(3), 279-290.

Marsh, C.J., \& Willis, G. (2007). Curriculum: Alternative approaches, ongoing issues. New Jersey: Pearson Prentice Hall.

Marsh, H. W., Balla, J. R., \& McDonald, R. P.(1988). Goodness-of-fit indexes in confirmatory factor analysis: The effect of sample size. Psychological Bulletin, 103, 391-410.

OECD, (2005). Formative assessment: Improving learning in secondary classrooms. Policy Brief, Retrieved from http://www.oecd.org/publications/Policybriefs/

Patton, M.Q. (1997). How to use qualitative methods in evaluation. Newbury park CA: SAGE Publications.

Schumacker, R. E., \& Lomax, R. G. (2004). A beginner's guide to structural equation modeling. New Jersey: Lawrence Erlbaum Ass.

Semerci, Ç. (2008). Eğitimde Ölçme ve Değerlendirme. Emin Karip (Ed), Ölçme ve Değerlendirme içinde, (s. 1-15). Ankara: Pegem Akademi.

Şencan, H. (2005). Sosyal ve davranışsal ölçümlerde güvenirlik ve geçerlilik. Ankara: Seçkin Yayınc1lik.

Şimşek, Ö. F. (2007). Yapısal eşitlik modellemesine giriş: Temel ilkeler ve lisrel uygulamaları. Ankara: Ekinoks Yayıncılık. 
Tabachnick, B. G., \& Fidell, L. S. (2001). Using multivariate statistics (Ed.), 4th Needham Heights. MA: Allyn \& Bacon.

Tabachnick, B. G., \& Fidell, L. S. (2007). Using multivariate statistics. Boston: Allyn and Bacon.

Taras, M. (2002). Using assessment for learning and learning from assessment. Assessment \& Evaluation in Higher Education, 27(6), 501-510.

Taras, M. (2003). To feedback or not to feedback in student self-assessment. Assessment \& Evaluation in Higher Education, 28(5), 549-565.

Yavuzer, H. (1994) Çocuk psikolojisi. Ankara: Remzi Kitapevi.

Yılmaz, V. \& Çelik, H. E. (2009). Lirsel ile yapısal eşitlik modellemesi-1. Ankara: Pegem Yayıncilik.

Yiğit, B. (2014). Ortaokul öğrencilerinin ders çalışma alışkanlıklarının incelenmesi (Yayınlanmamış Yüksek Lisans Tezi). Dicle Üniversitesi Eğitim Bilimleri Enstitüsi, Diyarbakır. 